\title{
CYTOTOXIC FLAVONOIDS FROM ERYTHRINA CAFFRA THUNB
}

\author{
Zelalem Yibralign Desta ${ }^{1,2,}$, Norbert Sewald ${ }^{2}$ and Runner R.T. Majinda ${ }^{3}$ \\ ${ }^{1}$ Department of Chemistry, Bahir Dar University, P.O. Box 79, Bahir Dar, Ethiopia \\ ${ }^{2}$ Department of Chemistry, Organic and Bioorganic Chemistry, Bielefeld University, P. O. Box \\ 100131, 33501 Bielefeld, Germany \\ ${ }^{3}$ Department of Chemistry, University of Botswana, Private Bag 0022, Gaborone, Botswana
}

(Received September 6, 2015; revised November 29, 2016)

\begin{abstract}
Erythrina caffra is an important medicinal plant native to South Africa. Its stem bark was investigated for the flavonoid constituents and biological activity. Some isolated flavonoids, 3, 5, 6, 8, 9, 10, 11, $12,13,15$ and 16 were found to be active against the human cervix carcinoma KB-3-1 cells with $\mathrm{IC}_{50}$ values in the micromolar range. Compounds $8,9,11,13$ and 15 also showed weak to moderate antibacterial activity against some organisms using the disc diffusion assay at loadings of $62.5 \mu \mathrm{g} / \mathrm{disc}(\mathbf{8}, \mathbf{1 1})$ and $125 \mu \mathrm{g} / \mathrm{disc}(\mathbf{9}, \mathbf{1 3}, \mathbf{1 5})$.
\end{abstract}

KEY WORDS: Erythrina caffra, Cytotoxicity, Antibacterial, Flavonoids, Fabaceae

\section{INTRODUCTION}

The genus Erythrina belongs to the family Fabaceae comprising over 110 species distributed in tropical and sub-tropical regions in both the southern and the northern hemispheres of the world as well as in some temperate regions of the world [1]. Erythrina caffra, the coast coral tree, is a tree native to south eastern Africa. It is widely appreciated for its warm red to scarlet-coloured flowers which appear from the cold winter months up to spring. It occurs in the warm and frostfree to light frost coastal regions of the Eastern Cape and Northern KwaZulu-Natal [2]. The bark of E. caffra is used to treat sores, tuberculosis, respiratory infections, wounds, abscesses, arthritis and toothache; infusions of the leaves are used as eardrops for earache; and decoctions of the roots are used for sprains [3]. Reports of phytochemical work on E. caffra are sporadic, with only a few secondary metabolites having been reported from different parts of the plant. In this paper we report antibacterial and cytotoxic flavonoids along with other compounds from $E$. caffra.

\section{RESULTS AND DISCUSSION}

Different extracts of E. caffra yielded a total of 29 compounds. The structure of these compounds were elucidated using ${ }^{1} \mathrm{H},{ }^{13} \mathrm{C}$ and $2 \mathrm{D}$ NMR data and by comparison with the literature values. These compounds included 20 flavonoids, 2 alkaloids, 3 terpenoids, 3 ferulic esters and 1 alcohol. The isolated compounds are erycaffra B 1, erycaffra A 2 [4], lysisteisoflavanone 3 [5], erycaffra E 4 [6], erycaffra C 5 [4], alpinumisoflavone 6 [7], erysubin B 7 [8], derrone 8 [9], warangalone 9 [10], isoerysenegalensein E 10 [5], erysenegalensein E 11 [11], laburnetin 12 [12], 8-prenylerythrinin C or senegalensin 13 [13], erythrinin C 14 [14], isosenegalensein 15 [5], burttinone 16 [15], erycaffra D 17 [6], erycaffra F 18 [6], abyssinoneV4'-methylether 19 [15], 8-oxo-erythrinine [16], 8-oxo-erythraline [17], oleanolic acid [18], $\beta$ amyrin [18], stigmasterol [19], octacosyl-E-ferulate [20], triacontyl-4-hydroxycinnamate [13], n-tetracosyl-p-coumarate [21] and octacosan-1-ol [22]. Only the structures of the flavonoids are reported in Figure 1.

*Corresponding author. E-mail: yibrazelalem@yahoo.com 
$\mathrm{HO}$<smiles>[R]c1c([R])c([R])c(C2COc3cc(C)cc(O)c3C2=O)c([R])c1[R]</smiles><smiles>[R]c1c([R])c(O)c2c(=O)c(-c3ccc(O)cc3)coc2c1[R]</smiles><smiles>[R]OC=[R]=[W]</smiles><smiles>[R]C=[R]C#[R]C1(C)C=CCC(C)(C)O1</smiles>

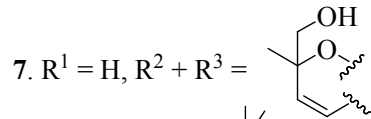

8. $\mathrm{R}^{1}+\mathrm{R}^{2}=\mathrm{R}_{1} \mathrm{R}^{3}=\mathrm{H}$

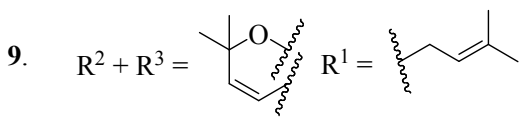

13.<smiles>[Tl]</smiles>
12. $\mathrm{R}^{1}=\mathrm{H}, \mathrm{R}^{2}=\mathrm{OH}, \mathrm{R}^{3}=$<smiles>[R][R]O</smiles>

14.

15
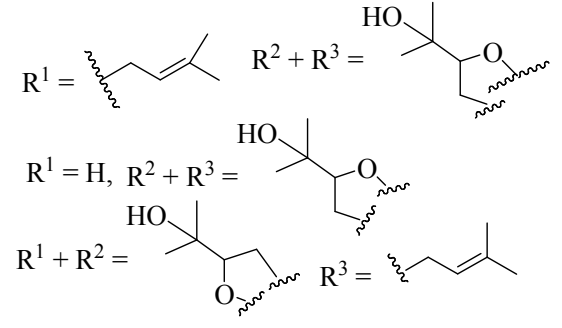<smiles>[R]c1cc(C2CC(=O)c3c(O)cc(O)cc3O2)cc([R])c1[R]</smiles>

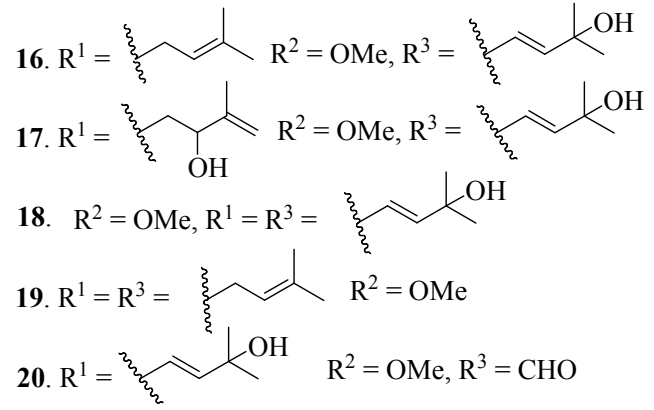

Figure 1. Chemical structures of some isolated pure compounds from E. caffra.

Cytotoxicity test

Seventeen pure compounds and six extracts were evaluated for cytotoxicity. The method used for this cytotoxicity test was the cell-based resazurin cytotoxicity assay with fluorescence readout. Human cervix carcinoma KB-3-1 cells were used and the reduction of the resazurin to resorufin was used as read out [23]. Of the seventeen pure isolates, compounds $\mathbf{3}, \mathbf{5}, \mathbf{6}, \mathbf{8 , 9}, \mathbf{1 0}$, 11, 12, 13, 15 and 16 were found to be active against the human cervix carcinoma KB-3-1 cells with $\mathrm{IC}_{50}$ values in the micromolar range (Table 1). Compounds 6, 9, 11, 13, 15 and 16 
exhibited greater cytotoxicity activity compared to the other compounds. Compounds $\mathbf{1 , ~ 2 , ~ 4 , ~ 7 , ~}$ 14, and $\mathbf{1 7}$ did not exhibit cytotoxicity against the human cervix carcinoma KB-3-1 cells. Five of the seventeen compounds $(\mathbf{1}, 2,4,5$ and 17$)$ were tested for the first time and only compound 5 exhibited greater cytotoxicity activity compared to the other four. On the other hand, compounds $3,8,9,10,11,12,13$, and 15 which exhibited cytotoxicity activity against the human cervix carcinoma KB-3-1 cells isolated and reported for the first time from E. caffra. Compounds $\mathbf{6}$ and $\mathbf{1 6}$ were previously isolated and reported from the stem bark of E. caffra [3]. Furthermore, compound $\mathbf{6}$ has been reported previously to exhibit significant cytotoxicity activity against $\mathrm{KB}$ cells with $\mathrm{ED}_{50}$ value of $4.13 \mu \mathrm{g} / \mathrm{mL}(12.3 \mu \mathrm{M})$ [7]. The cytotoxicity tests were also performed on the crude extracts and only the $n$-hexane and ethyl acetate extracts of the root bark were active against the human cervix carcinoma KB-3-1 cells at concentrations of $0.11 \mathrm{mg} / \mathrm{mL}$ and $0.06 \mathrm{mg} / \mathrm{mL}$, respectively. However, other crude extracts were not active against the human cervix carcinoma KB-3-1 cells (Table 1). Finally it could be concluded that isoflavones exhibited a significant and higher cytotoxicity compared to other compounds, for instance, isoflavanones.

Table 1. Cytotoxicity data for some isolates and crude extracts from E. caffra.

\begin{tabular}{|c|c|c|c|}
\hline Samples & Concentration & $\mathrm{IC}_{50}(\mu \mathrm{M})$ & Activity \\
\hline $\mathbf{1}$ & $0.1 \mathrm{~mol} / \mathrm{L}$ & - & na \\
\hline $\mathbf{2}$ & $0.1 \mathrm{~mol} / \mathrm{L}$ & - & na \\
\hline $\mathbf{3}$ & $0.1 \mathrm{~mol} / \mathrm{L}$ & 183 & na \\
\hline $\mathbf{4}$ & $0.1 \mathrm{~mol} / \mathrm{L}$ & - & a \\
\hline $\mathbf{5}$ & $0.1 \mathrm{~mol} / \mathrm{L}$ & 104 & a \\
\hline $\mathbf{6}$ & $0.1 \mathrm{~mol} / \mathrm{L}$ & 71.4 & a \\
\hline $\mathbf{7}$ & $0.1 \mathrm{~mol} / \mathrm{L}$ & - & a \\
\hline $\mathbf{8}$ & $0.1 \mathrm{~mol} / \mathrm{L}$ & 230 & a \\
\hline $\mathbf{9}$ & $0.1 \mathrm{~mol} / \mathrm{L}$ & 73.4 & a \\
\hline $\mathbf{1 0}$ & $0.1 \mathrm{~mol} / \mathrm{L}$ & 99.0 & a \\
\hline $\mathbf{1 1}$ & $0.1 \mathrm{~mol} / \mathrm{L}$ & 58.4 & a \\
\hline $\mathbf{1 2}$ & $0.1 \mathrm{~mol} / \mathrm{L}$ & 250 & na \\
\hline $\mathbf{1 3}$ & $0.1 \mathrm{~mol} / \mathrm{L}$ & 37.8 & a \\
\hline $\mathbf{1 4}$ & $0.1 \mathrm{~mol} / \mathrm{L}$ & - & a \\
\hline $\mathbf{1 5}$ & $0.1 \mathrm{~mol} / \mathrm{L}$ & 53.8 & na \\
\hline $\mathbf{1 6}$ & $0.1 \mathrm{~mol} / \mathrm{L}$ & 58.8 & na \\
\hline $\mathbf{1 7}$ & $0.1 \mathrm{~mol} / \mathrm{L}$ & - & na \\
\hline HS & $0.25 \mathrm{mg} / \mathrm{mL}$ & - & na \\
\hline EAS & $0.25 \mathrm{mg} / \mathrm{mL}$ & - & a \\
\hline MS & $0.25 \mathrm{mg} / \mathrm{mL}$ & - & a \\
\hline HR & $0.11 \mathrm{mg} / \mathrm{mL}$ & - & na \\
\hline EAR & $0.06 \mathrm{mg} / \mathrm{mL}$ & - & - \\
\hline MR & $0.25 \mathrm{mg} / \mathrm{mL}$ & - & \\
\hline
\end{tabular}

Key: HS: $n$-hexane extract of the stem bark; EAS: ethyl acetate extract of the stem bark; MS: methanol extract of the stem bark; HR: $n$-hexane extract of the root bark; EAR: ethyl acetate extract of the root bark and MR: methanol extract of the root; a: active; na: not active.

\section{Antibacterial test}

Seventeen pure compounds were evaluated for antibacterial activity, together with six crude extracts from the stem and root bark of E. caffra, using the disc diffusion assay (Table 2). The microorganisms for the test were collected from Deutsche Sammlung von Mikroorganismen und Zellkulturen (DSMZ) collection (German Collection of Microorganisms and Cell Cultures) (Braunschweig, Germany). The non-pathogenic model organisms, Escherichia coli (DSMZ 
1058), Pseudomonas agarici (DSMZ 11810), Bacillus subtilis (DSMZ 704), Micrococcus luteus (DSMZ 1605), Streptococcus ferus (DSMZ 18308) and Streptococcus minor (DSMZ 17118) were used for the antibacterial test on pure compounds and crude extracts from E. caffra. According to the test result, only few isolated pure compounds and crude extracts exhibited weak to moderate inhibition $(\mathrm{ZOI}=8-12 \mathrm{~mm}$ ) against some of the bacteria. Most of the isolated pure compounds and crude extracts did not display any inhibition $(\mathrm{ZOI}=0 \mathrm{~mm})$ against the test organisms. Among the tested compounds, compound $\mathbf{8}$ exhibited an intermediate inhibition against E. coli, B. subtilis, $P$. agarici and $S$. minor whereas compounds $\mathbf{9}$ and $\mathbf{1 1}$ displayed an intermediate inhibition against $E$. coli and $S$. minor. Furthermore, compound $\mathbf{1 3}$ also showed some activity against $E$. coli and $B$. subtilis and compound $\mathbf{1 5}$ showed an intermediate inhibition against $E$. coli, B. subtilis and $P$. agarici. In previous work compound $\mathbf{6}$ had been evaluated for antibacterial activity using the disc diffusion method and did not exhibit significant inhibition against $E$. coli and B. subtilis [24]. In the microtitre bioassay method, however, compounds 6 and $\mathbf{1 6}$ are reported to exhibit significant antibacterial activity against E. coli and B. subtilis [3].

Table 2. Antibacterial activity test results for isolated pure compounds and crude extracts from E. caffra using the disc diffusion method.

\begin{tabular}{|c|c|c|c|c|c|c|c|c|}
\hline \multirow[t]{2}{*}{ Samples } & \multirow{2}{*}{$\begin{array}{c}\text { Stock } \\
\text { solution } \\
\mathrm{mg} / \mathrm{mL}\end{array}$} & \multirow{2}{*}{$\begin{array}{c}\text { Loading dose } \\
\mu \mathrm{g}\end{array}$} & \multicolumn{6}{|c|}{ Type of bacteria used for tests } \\
\hline & & & $\begin{array}{c}E . \\
\text { coli }\end{array}$ & $\begin{array}{c}B . \\
\text { subtils }\end{array}$ & $\begin{array}{c}P . \\
\text { agarici }\end{array}$ & $\begin{array}{c}\text { M. } \\
\text { luteus }\end{array}$ & $\begin{array}{c}S . \\
\text { ferus }\end{array}$ & $\begin{array}{c}S . \\
\text { minor }\end{array}$ \\
\hline 1 & 2 & 50 & - & - & - & - & - & - \\
\hline 2 & 2 & 50 & - & - & - & - & - & - \\
\hline 3 & 2 & 50 & - & - & - & - & - & - \\
\hline 4 & 2 & 50 & - & - & - & - & - & - \\
\hline 5 & 2 & 50 & - & - & - & - & - & - \\
\hline 6 & 2 & 50 & - & - & - & - & - & - \\
\hline 7 & 2.5 & 62.5 & - & - & - & - & - & - \\
\hline 8 & 2.5 & 62.5 & + & + & + & - & - & + \\
\hline 9 & 5 & 125 & + & - & - & - & - & + \\
\hline 10 & 5 & 125 & - & - & - & - & - & - \\
\hline 11 & 2.5 & 62.5 & + & - & - & - & - & + \\
\hline 12 & 5 & 125 & - & - & - & - & - & - \\
\hline 13 & 5 & 125 & + & + & - & - & - & - \\
\hline 14 & 2.5 & 62.5 & - & - & - & - & - & - \\
\hline 15 & 5 & 125 & + & + & + & - & - & - \\
\hline 16 & 5 & 125 & - & - & - & - & - & - \\
\hline 17 & 2.5 & 62.5 & - & - & - & - & - & - \\
\hline $\mathrm{HS}$ & 5 & 125 & - & - & - & - & - & - \\
\hline EAS & 4 & 100 & - & - & - & - & - & - \\
\hline MS & 5 & 125 & - & - & - & - & - & - \\
\hline HR & 5 & 125 & - & - & - & - & - & - \\
\hline EAR & 5 & 125 & + & + & - & - & - & + \\
\hline MR & 5 & 125 & - & - & - & - & - & - \\
\hline Amp & 100 & 2.5 & +++ & +++ & +++ & +++ & +++ & +++ \\
\hline
\end{tabular}

Key: +: intermediate $(\mathrm{ZOI}=8-12 \mathrm{~mm})$, -: resistant $(\mathrm{ZOI}=0)$ and $+++:$ strong activity $(\mathrm{ZOI}=17-19 \mathrm{~mm})$ of the standard (ampicillin) against the given microorganisms. HS: $n$-hexane extract of the stem bark; EAS: ethyl acetate extract of the stem bark; MS: methanol extract of stem bark; HR: $n$-hexane extract of the root bark; EAR: ethyl acetate extract of the root bark and MR: methanol extract of the root bark; Amp: ampicillin.

In Agar Overlay Technique compound $\mathbf{6}$ also exhibited significant antibacterial activities against E. coli and B. Subtilis [25]. It thus appears that the disc diffusion method is rather insensitive as evidenced by the lacking activity of compounds 6 and 16, while these same compounds were active according to the other two methods. The problem could be that the compounds are not 
diffusing well from the disc in to the agar and hence false-negative results are observed. The crude extracts of the stem and root bark of E. caffra were also evaluated for antibacterial test using disc diffusion method and only the crude ethyl acetate extract of the root bark exhibited an intermediate inhibition against E. coli, B. subtilis, and S. minor.

\section{EXPERIMENTAL}

\section{General}

${ }^{1} \mathrm{H}$ NMR, ${ }^{13} \mathrm{C}$ NMR, DEPT, COSY, HMQC and HMBC of the compounds were recorded using Bruker Avance DPX 300, DRX 500 and DRX $600 \mathrm{MHz}$ spectrometers using standard pulse sequences and referenced to residual solvent signals. HREI-MS was determined using GCT Premier Spectrometer. Column chromatography was carried out on silica gel $60(0.040-0.063$ $\mathrm{mm}$, Merck) and Sephadex LH-20 as the stationary phases. Preparative TLC (0.5 mm thick) and analytical TLC were performed with precoated Merck silica gel 60 PF254+366. Visualisation of chromatograms were done under UV light $(254$ and $366 \mathrm{~nm})$ and further by spraying vanillinsulfuric acid spray followed by heating. The ultraviolet and visible (UV-Vis) spectra were measured on Spectro UV-Vis Double Beam PC8 scanning auto Cell UVD-3200, LABOMED, INC. Infrared (IR) absorptions were measured on a PerkinElmer FT-IR Spectrometer, Spectrum Two, PerkinElmer UATR Two. Optical rotation was determined by using an Autopol IV automatic polarimeter.

\section{Plant material}

Stem bark of E. caffra Thunb was collected from experimental garden, University of Botswana, Gaborone, Botswana in February 2011. The species was identified by Mr. M. Muzila and a voucher specimen, Ec-25-11, has been deposited at the University of Botswana Herbarium.

\section{Extraction and isolation}

The air-dried $600 \mathrm{~g}$ of stem bark of E. caffra was ground and extracted by soaking successively in $n$-hexane, EtOAc and $\mathrm{MeOH}$ each for 24 hours (three times with each solvent) and removal of the solvent under reduced pressure using a BUCHI flash evaporator to afford black gummy extracts of $5.0 \mathrm{~g}$ (for n-hexane), $29.5 \mathrm{~g}$ (for EtOAc) and $18.8 \mathrm{~g}$ (for $\mathrm{MeOH}$ ).

The EtOAc extract $(29.5 \mathrm{~g}$ ) was fractionated by vacuum liquid chromatography (VLC) on silica gel (500 g), eluting with $n$-hexane containing increasing amounts of EtOAc (up to $100 \%$ ), followed by $\mathrm{EtOAc} / \mathrm{MeOH}$ by increasing the amounts of $\mathrm{MeOH}$ (up to $100 \%$ ) to yield a total of 40 fractions of $200 \mathrm{~mL}$ each. Fractions that showed similar components on TLC analysis were combined together to give thirteen main fractions labelled A to M, respectively.

The combined fraction $\mathbf{C}$ from VLC (5-10) (3.0 g) was adsorbed onto $6.0 \mathrm{~g}$ of silica gel and applied on a column that was packed with $90.0 \mathrm{~g}$ of silica gel in $n$-hexane and eluted with $n$ hexane/EtOAc by increasing the amounts of EtOAc (up to $100 \%$ ) followed by EtOAc/MeOH (up to 7:3) and yielded a total of 30 sub-fractions of $50 \mathrm{~mL}$ each. Of the 30 sub-fractions, subfractions 1-5 were combined together and passed through Sephadex LH-20 using the solvent system $\mathrm{CHCl}_{3} / \mathrm{MeOH}(1: 1)$ and yielded a total of $5 \mathrm{sub}$-fractions of $100 \mathrm{~mL}$ each. Of the five sub-fractions, sub-fraction $3(1.5 \mathrm{~g})$ was adsorbed onto $4.0 \mathrm{~g}$ of silica gel and applied on a column that was packed with $90.0 \mathrm{~g}$ of silica gel and eluted with $n$-hexane/chloroform solvent system by increasing amounts of $\mathrm{CHCl}_{3}$ (up to $100 \%$ ), followed by $\mathrm{CHCl}_{3} / \mathrm{MeOH}$ with increasing amounts of $\mathrm{MeOH}$ (up to $100 \%$ ) and afforded 3 pure compounds triacontyl-4hydroxycinnamate $(12.2 \mathrm{mg})$, octacosyl-E-ferulate $(84.2 \mathrm{mg})$ and octacosan-1-ol $(7.2 \mathrm{mg})$. Other components were long chain fatty acids and further work was not done. 
The combined fraction D from VLC (11-12) (1.70 g) was passed through Sephadex LH-20 using $\mathrm{MeOH} / \mathrm{CHCl}_{3}(1: 1)$ as the solvent system and yielded a total of $22 \mathrm{sub}$-fractions of $15 \mathrm{~mL}$ each. Based on TLC analysis these 22 sub-fractions were classified as 1-7 (a), 8-12 (b), 13-15 (c) and 16-22 (d). The sub-fraction (c) was applied on preparative TLC plate and eluted with the solvent system $n$-hexane/EtOAc/ $\mathrm{CHCl}_{3}(7: 2: 1)$ and afforded the two pure compounds 19 (2.4 $\mathrm{mg})$ and $9(6.9 \mathrm{mg})$. The sub-fraction (d) was applied on the preparative TLC and eluted with the solvent system $n$-hexane/EtOAc $/ \mathrm{CHCl}_{3}(6: 3: 1)$ and afforded one pure compound 11 (7.3 $\mathrm{mg}$ ). Other sub-fractions (a) and (b) gave long chain fatty compounds and did not show any interesting results on TLC and were thus discarded.

The combined fraction $\mathbf{E}$ from VLC (13-15) (2.0 g) was adsorbed onto $6.0 \mathrm{~g}$ of silica gel and applied on a column which was packed with $80.0 \mathrm{~g}$ of silica gel using a solvent $\mathrm{n}$ hexane/EtOAc (7:3) system and eluted with $n$-hexane/EtOAc (7:3) solvent system by increasing the amounts of EtOAc (up to $100 \%$ ), followed by EtOAc/MeOH by increasing the amounts of $\mathrm{MeOH}$ and yielded a total of 30 sub-fractions of $25 \mathrm{~mL}$ each. Of the 30 sub-fractions, subfraction 8 was pure and afforded an isoflavonoid $6(88 \mathrm{mg})$. The sub-fractions 9-11 were combined together and applied onto a column which was packed with $60 \mathrm{~g}$ of silca gel and eluted with $n$-hexane/EtOAc (3:2) solvent system by increasing the amounts of EtOAc (up to $100 \%)$ and afforded the two pure compounds oleanolic acid $(14.0 \mathrm{mg})$ and $\beta$-amyrin $(2.8 \mathrm{mg})$. The sub-fractions 12-17 were combined together and applied onto a column which was packed with $30.0 \mathrm{~g}$ of silica gel and eluted with $n$-hexane/EtOAc (7:3) solvent system by increasing the amounts of EtOAc (up to $100 \%$ ), followed by EtOAc/MeOH (7:3) system and yielded a total of 20 sub-fractions of $25 \mathrm{~mL}$ each. Of these 20 sub-fractions, sub-fractions 9-13 were combined together and applied on the preparative TLC and eluted with the solvent system $\mathrm{DCM} / n$ hexane/MeOH (7:2:1) (2 developments) and afforded two prenylated isoflavonoids $\mathbf{1}(8.0 \mathrm{mg})$ and $2(7.0 \mathrm{mg})$.

The combined fraction $\mathbf{F}$ from VLC (16-20) $(4.0 \mathrm{~g})$ was adsorbed onto $6.0 \mathrm{~g}$ of silica gel and applied onto a column which was packed with $120.0 \mathrm{~g}$ of silica gel and eluted with $n$ hexane/EtOAc (7:3) by increasing the amounts of EtOAc (up to 100\%), followed by EtOAc/MeOH (7:3) and yielded a total of 39 sub-fractions of $25 \mathrm{~mL}$ each. These sub-fractions were combined together based on the TLC analysis to give a total of 5 main sub-fractions labelled (a) to (e), respectively. Of these 5 sub-fractions, sub-fraction (b) (3-6) was applied on preparative TLC and eluted with the solvent system $n$-hexane/EtOAc (4:1) and afforded one pure compound $n$-tetracosyl-p-coumarate $(8 \mathrm{mg})$. The sub-fraction (c) (7-19) (2.0 g) was adsorbed onto $6.0 \mathrm{~g}$ of silica gel and applied onto a column which was packed with $80.0 \mathrm{~g}$ of silica gel and eluted with $n$-hexane/EtOAc (7:3) solvent system by increasing the amounts of EtOAc (up to $100 \%$ ), followed by EtOAc/ $\mathrm{MeOH}$ upto (7:3) and yielded a total of 25 subfractions of $25 \mathrm{~mL}$ each. Of these $25 \mathrm{sub}$-fractions, sub-fractions 9-11 were combined together and applied on preparative TLC plate and eluted with the solvent system DCM $/ n$-hexane $/ \mathrm{MeOH}$ (5:4.5:0.5) (2 developments) and afforded the two pure compounds $5(7.5 \mathrm{mg})$ and $\mathbf{1 0}(14.8 \mathrm{mg})$. The sub-fraction (d) (20-30) was passed through Sephadex LH-20 using the solvent system $\mathrm{CHCl}_{3} / \mathrm{MeOH}(1: 1)$ and yielded a total of 15 sub-fractions of $10 \mathrm{~mL}$ each. Based on TLC analysis, the sub-fractions that showed similar components on TLC were combined together in to 2 main sub-fractions labelled as 1-8 and 9-15. The first sub-fraction 1-8 contained long chains and chlorophyll and further work was not done. However, the sub-fractions 9-15 were combined together and applied on the preparative TLC plate and eluted with the solvent system $\mathrm{DCM} / n$ hexane/MeOH (5:4:1) (3 developments) and afforded the three pure compounds 8 (3.2 $\mathrm{mg}), \mathbf{1 2}$ (15.4 mg) and 3 (10.0 mg). The sub-fraction (e) (21-39) was not further analyzed due to lack of interesting components on TLC plate.

The combined fraction $\mathbf{G}$ from VLC (21-23) (3.0 g) was adsorbed onto $4.5 \mathrm{~g}$ of silica gel and applied onto a column which was packed with $100.0 \mathrm{~g}$ of silica gel and eluted with $n$ hexane/EtOAc (7:3) solvent system by increasing the amounts of EtOAc (up to 100\%), followed 
by $\mathrm{EtOAc} / \mathrm{MeOH}(9: 1)$ and yielded a total of 28 sub-fractions. These 28 sub-fractions were combined based on TLC analysis to give five main sub-fractions and classified as 1-6 (a), 7-10 (b), 11-13 (c), 14-16 (d) and 17-28 (e). Of these five main sub-fractions, sub-fraction (b) was applied on preparative TLC plate and eluted with the solvent system $n$-hexane/EtOAc/ $\mathrm{CHCl}_{3}$ (5:4:1) (3 developments) and afforded one pure compound 17 (5.2 mg). The sub-fraction (c) was applied on preparative TLC plate and eluted with the solvent system $n$-hexane $/ \mathrm{CHCl}_{3} / \mathrm{MeOH}$ (5:4:1) (2 developments) and afforded one pure compound $13(25 \mathrm{mg})$. The sub-fraction (d) was applied on the preparative TLC plate and eluted with the solvent system $n$-hexane/EtOAc/ $\mathrm{CHCl}_{3}$ (5:4:1) (2 developments) and afforded the two pure compounds $\mathbf{1 5}(15.7 \mathrm{mg})$ and $\mathbf{1 6}(15.0 \mathrm{mg})$. The sub-fraction (e) did not show any interesting results on TLC plate and was thus discarded.

The combined fraction $\mathbf{H}$ from VLC (24-26) (2.80 g) was passed through Sephadex LH-20 using the solvent system $\mathrm{CHCl}_{3} / \mathrm{MeOH}(1: 1)$ and yielded a total of 21 sub-fractions of $10 \mathrm{~mL}$ each. Based on TLC analysis, the sub-fractions that showed similar components on TLC plate were combined together to give 3 main sub-fractions. The sub-fractions 1-7 and 8-14 did not show any interesting results on TLC plate and were thus discarded. The sub-fractions 15-21 were combined together and applied on preparative TLC plate and eluted with the solvent system $n$-hexane/EtOAc/ $\mathrm{CHCl}_{3} / \mathrm{MeOH}$ (5:3:1.5:0.5) (3 developments) and afforded three pure compounds $4(4.9 \mathrm{mg}), \mathbf{1 4}(4.9 \mathrm{mg})$ and $7(4.2 \mathrm{mg})$.

The combined fraction I from VLC (27-28) (2.00 g) was passed through Sephadex LH-20 using the solvent system $\mathrm{CHCl}_{3} / \mathrm{MeOH}(1: 1)$ and yielded a total of 13 sub-fractions of $10 \mathrm{~mL}$ each. Based on TLC analysis, the sub-fractions that showed similar components on TLC were combined together to give 2 main sub-fractions. The sub-fractions 1-5 did not show any interesting results on TLC and were thus discarded. The sub-fractions 6-13 were combined and passed through Sephadex LH-20 using the solvent system $\mathrm{CHCl}_{3} / \mathrm{MeOH}(1: 1)$ and yielded a total of 10 sub-fractions of $10 \mathrm{~mL}$ each. Based on TLC analysis, the sub-fractions that showed similar components on TLC were combined together to give 2 main sub-fractions. The subfractions 1-4 did not show any interesting results on TLC and were thus discarded. The subfractions from 5-10 were combined and applied on preparative TLC plate and eluted with the solvent system $n$-hexane/EtOAc/DCM (4:4:2) (3 developments) and afforded the pure compound 20 ( $2.0 \mathrm{mg})$.

The combined fraction $\mathbf{J}$ from VLC (29-31) (1.10 g) was passed through Sephadex LH-20 using the solvent system $\mathrm{CHCl}_{3} / \mathrm{MeOH}(1: 1)$ and yielded a total of 20 sub-fractions of $10 \mathrm{~mL}$ each. Based on TLC analysis, the sub-fractions that showed similar components on TLC were combined together to give 2 main sub-fractions. The sub-fractions 1-7 did not show any interesting results on TLC and were thus discarded. The sub-fractions 8-20 were combined and passed through Sephadex LH-20 using the solvent system $\mathrm{CHCl}_{3} / \mathrm{MeOH}$ (1:1) and yielded a total of $10 \mathrm{sub}$-fractions of $10 \mathrm{~mL}$ each. Based on TLC analysis, the sub-fractions that showed similar components on TLC were combined together to give 2 main sub-fractions. The subfractions 1-3 did not show any interesting results on TLC and were thus discarded. The subfractions from 4-10 were combined and applied on preparative TLC plate and eluted with the solvent system $n$-hexane/EtOAc/ $\mathrm{CHCl}_{3} / \mathrm{MeOH}$ (5:3:1.5:0.5) (3 developments), which afforded the pure compound $18(4.1 \mathrm{mg})$.

The combined fraction K (32-33) (1.0 g) was passed through Sephadex LH-20 using the solvent system $\mathrm{CHCl}_{3} / \mathrm{MeOH}(1: 1)$ and yielded a total of $15 \mathrm{sub}$-fractions of $10 \mathrm{~mL}$ each. Based on TLC analysis, the sub-fractions that showed similar components on TLC were combined together to give 2 main sub-fractions. The sub-factions 1-7 did not show any interesting results on TLC and were thus discarded. The sub-fractions 8-15 were combined and passed through Sephadex LH-20 using the solvent system $\mathrm{CHCl}_{3} / \mathrm{MeOH}(1: 1)$ and yielded total of 8 subfractions of $10 \mathrm{~mL}$ each. Based on TLC analysis, the sub-fractions that showed similar components on TLC were combined together to give 2 main sub-fractions. The sub-factions 1-3 did not show any interesting results on TLC and were thus discarded. The sub-fractions from 4- 
8 were combined together and applied on preparative TLC plate and eluted with the solvent system $n$-hexane/EtOAc/DCM (4:4:2) (2 developments) and afforded one pure alkaloid 8-oxoerythrinine (4.5 mg).

\section{Cytotoxicity test}

Cytotoxic activity of the isolates and crude extracts was done as described [23]. Briefly the KB3-1 cells were cultivated as a monolayer in a DMEM (Dulbecco's Modified Eagel Medium) with glucose $(4.5 \mathrm{~g} / \mathrm{L}), \mathrm{L}$-glutamine, sodium pyruvate and phenol red, supplemented with $10 \%$ (KB-3-1) foetal bovine serum (FBS). The cells were maintained at $37{ }^{\circ} \mathrm{C}$ and $5.3 \% \mathrm{CO}_{2}$ humidified air. On the day before the test, the cells (70\% confluence) were detached with trypsin-ethylenediamine tetraacetic acid (EDTA) solution $(0.05 \% ; 0.02 \%$ in DPBS (Dulbecco's Phosphate Buffered Saline) and placed in sterile 96-well plates in a density of 1000 cells in 100 $\mu \mathrm{L}$ medium per well. The dilution series of the compounds were prepared from stock solutions in DMSO of concentrations of $100 \mathrm{mM}, 50 \mathrm{mM}$ or $25 \mathrm{mM}$. The stock solutions were diluted with culture medium (10\% FBS [KB-3-1]) down to pM range. The dilution prepared from stock solution was added to the wells. Each concentration was tested in six replicates. Dilution series were prepared by pipetting liquid from well to well. The control contained the same concentration of DMSO as the first dilution. After incubation for $72 \mathrm{~h}$ at $37{ }^{\circ} \mathrm{C}$ and $5.3 \% \mathrm{CO}_{2}$ humidified air, $30 \mu \mathrm{L}$ of an aqueous resazurin solution $(175 \mu \mathrm{M})$ was added to each well. The cells were incubated under the same conditions for 5 hours. Subsequently, the fluorescence was measured. The excitation was effected at a wave length of $530 \mathrm{~nm}$, whereas the emission was recorded at a wavelength of $588 \mathrm{~nm}$. The $\mathrm{IC}_{50}$ values were calculated as a sigmoidal dose response curve using GRAPHPAD PRISM 4.03. The $\mathrm{IC}_{50}$ values equal the drug concentration, at which vitality is $50 \%$.

\section{Antibacterial test}

Simple antibacterial test for the isolated pure compounds and crude extracts from Erythrina caffra was done using disc diffusion method. In this method, a Petri dish with a nutrient broth agar was plated with $3 \mathrm{~mL}$ of a bacteria solution from a culture with an optical density of 0.2 . The plated bacteria were incubated at $37{ }^{\circ} \mathrm{C}$ for $30 \mathrm{~min}$. The sterilized paper discs were loaded with $25 \mu \mathrm{L}$ of solution of pure compounds or extracts dissolved in DMSO. The discs were allowed to dry and then placed on seeded agar plate using sterilized forceps. The plates were then incubated at $37^{\circ} \mathrm{C}$ for 24 hours, after which zones of inhibition, if any, were measured. For inactive compounds no zone of inhibition was observed. Concentration ranges from 2.0 to 5.0 $\mathrm{mg} / \mathrm{mL}$ corresponding to loading doses of $50-125 \mu \mathrm{g} /$ disc were used. The diameters of the zones of inhibition were measured in millimetres. Ampicillin (loading of $2.5 \mu \mathrm{g} / \mathrm{disc}$ or $25 \mu \mathrm{L}$ of 100 $\mu \mathrm{g} / \mathrm{mL}$ ampicillin solution) was used as a standard. The diameter of the zone of inhibition for ampicillin under these conditions ranged from 17-19 mm.

\section{ACKNOWLEDGEMENTS}

We are grateful for the financial support from Deutscher Akademischer Austauschdienst (DAAD, German Academic Exchange Service). We also thank C. Michalek for performing bioactivity tests. Zelalem Yibralign Desta also thanks University of Gondar for study leave and Professor R.R.T. Majinda also thanks University of Botswana for a research facility. 


\section{REFERENCES}

1. Tanaka, H.; Oh-Uchi, T.; Etoh, H.; Sako, M.; Asai, F.; Fukai, T.; Sato, M.; Murata, J.; Tateishi, Y. Phytochemistry 2003, 64, 753.

2. Olajuyigbe, O.O.; Afolayan, A.J. J. Med. Plants Res. 2012, 69, 1713.

3. Chukwujekwu, J.C.; Van Heerden, F.R.; Van Staden, J. Phytother. Res. 2011, 25, 46.

4. Desta, Z.Y.; Majinda, R.R.T. Nat. Prod. Commun. 2014, 9, 817.

5. El-Masry, S.; Amer, M.E.; Abdel-Kader, M.S.; Zaatout, H.H. Phytochemistry 2002, 60, 783.

6. Desta, Z.Y.; Sewald, N.; Majinda, R.R.T. Nat. Prod. Res. 2014, 28, 667.

7. Nkengfack, A.E.; Azebaze, A.G.B.; Waffo, A.K.; Fomuma, Z.T.; Meyer, M.; Heerden, F.R.V. Phytochemistry 2001, 58, 1113.

8. Tanaka, H.; Tanaka, T.; Etoh, H.; Watanabe, N.; Ahmad, M.; Qurashi, I., Khand, M.R. Heterocycles 1998, 48, 2661.

9. Lee, J.; Oh, W.K.; Ahn, J.S.; Kim, Y.H.; Mbafor, J.T.; Wandji, J.; Fomum, Z.T. Planta Med. 2009, 75, 268.

10. Bae, E.Y.; Na, M.; Njamen, D.; Mbafor, J.T.; Fomum, Z.T.; Cui, L.; Choung, D.H.; Kim, B.Y.; Oh, W.K.; Ahn, J.S. Planta Med. 2006, 72, 945.

11. Wandji, J.; Fomum, Z.T.; Tillequin, F.; Seguin, E.; Koch, M. Phytochemistry 1994, 35, 245.

12. Sato, M.; Tanaka, H.; Tani, N.; Nagayama, M.; Yamaguchi, R. Lett. Appl. Microbiol. 2006, 43, 243.

13. Wandji, J.; Nkengfack, A.E.; Fomum, Z.T.; Ubillas, R.; Killday, K.B.; Tempesta, M.S. J. Nat. Prod. 1990, 53, 1425.

14. Deshpande, V.H.; Pendse, A.D.; Pendse, R. Indian J. Chem. 1977, 15B, 205.

15. Yenesew, A., Midiwo, J.O., Miessner, M., Heydenreichb, M., Peter, M.G. Phytochemistry 1998, 48, 1439.

16. Dagne, E.; Steglich, W. Phytochemistry 1984, 23, 449.

17. Mohammed, M.M.D.; Ibrahim, N.A.; Awad, N.E.; Matloub, A.A.; Mohamed-Ali, A.G.; Barakat, E.E.; Mohamed, A.E.; Colla, P.L. Nat. Prod. Res., 2011, iFirst, 1-11.

18. Wandji, J.; Awanchiri, S.S.; Fomum, Z.T.; Fillequin, F.; Libot, F. Phytochemistry 1995, 39, 677.

19. Isah, Y.; Ndukwe, I.G.; Amupitan, J.O. World J. Life Sci. and Med. Res. 2012, 2, 77.

20. Nkengfack, A.E.; Sanson, D.R.; Tempesta, M.S. J. Nat. Prod. 1989, 52, 320.

21. Abdel-Kader, M.S.; Amer, M.E.; Tang, S.; Kingston, D.G. Nat. Prod. Res. 2006, $20,922$.

22. EI-Masry, S.; Hammoda, H.M.; Zaatout, H.H.; Alqasoum, S.I.; Abdel-Kader, M.S. Nat. Prod. Sci. 2010, 16, 211.

23. Sammet, B.; Bogner,T.; Nahrwold, M.; Weiss, C.; Sewald, N. J. Org. Chem. 2010, 75, 6953.

24. Rahman, M.Z.; Sultana, S.J.; Faruquee, C.F.; Ferdous, F.; Rahman, M.S.; Islam, M.S.; Rashid, M.A. J. Saudi Pharm. 2007, 15, 140.

25. Juma, B.F.; Majinda, R.R.T. 11 ${ }^{\text {th }}$ NAPRECA Symposium Book of Proceedings, Antananarivo, Madagascar; 2009, p 97. 